\title{
Finite element modelling of a solar collector
}

\author{
A. Álvarez ${ }^{1}$, M.C. Muñiz ${ }^{2}$ L.M. Varela ${ }^{3}$, O. Cabeza ${ }^{4}$ \\ ${ }^{1}$ Departamento de Construcciones Navales \\ E.U. Politécnica, Universidad de La Coruña \\ Avda. 19 de febrero s/n, 15405 La Coruña (Spain) \\ Phone number:+ 34 981337400. Ext. 3097, email: aalvarez@udc.es \\ ${ }^{2}$ Departamento de Matemática Aplicada \\ Facultad de Matemáticas, Universidad de Santiago de Compostela \\ Campus sur, 15782 Santiago de Compostela (Spain) \\ Phone number:+34 981 563100. Ext. 13354, email: mcarmen.muniz@usc.es \\ ${ }^{3}$ Departamento Física de la Materia Condensada \\ Facultad de Física, Universidad de Santiago de Compostela \\ Campus sur, 15782 Santiago de Compostela (Spain) \\ Phone number:+34 981 563100. Ext. 13966, email: luismiguel.varela@usc.es \\ ${ }^{4}$ Departamento de Física \\ Facultad de Ciencias, Universidad de La Coruña \\ Campus de la Zapateira s/n, 15071 La Coruña (Spain) \\ Phone number:+ 34 981337400. Ext. 2063, email: oscabe@udc.es
}

\begin{abstract}
A mathematical model of a serpentine flat-plate solar collector using finite elements is presented. The numerical simulations focus on the thermal and hydrodynamic behaviour of the collector. The energy equation is numerically solved, as are the Navier-Stokes equations for an incompressible fluid. Numerical results involving one part of the serpentine are also shown.
\end{abstract}

\section{Key words}

Renewable energy, solar collector, FEM simulation.

\section{Introduction}

Over the past few years, the population around the world is more aware how using renewable energies can help preventing environmental pollution.

Nowadays, energy is considered a key factor in economic development. For this reason serious efforts are being made in research to study and improve all the processes related to renewable energies. As a consequence, a great number of studies has been published [4, 5, 6, 7] and many kinds of solar collectors were designed and built.

This study presents a numerical modelling of a flat-plate solar collector with a corrugated inner shape. It is built with economical materials, such as aluminium. A twodimensional, both stationary and transient analysis is developed to obtain the main thermal parameters of the collector. Moreover, three-dimensional thermal and hydrodynamic simulations are performed on one part of the serpentine.

\section{Two-dimensional thermal analysis}

In a first approximation towards the numerical simulation of the collector, a simplified two-dimensional thermal model coupled with a one dimensional model in the fluid are introduced, the computational domain being a crosssection of the collector corresponding to one duct (see Figure 1).

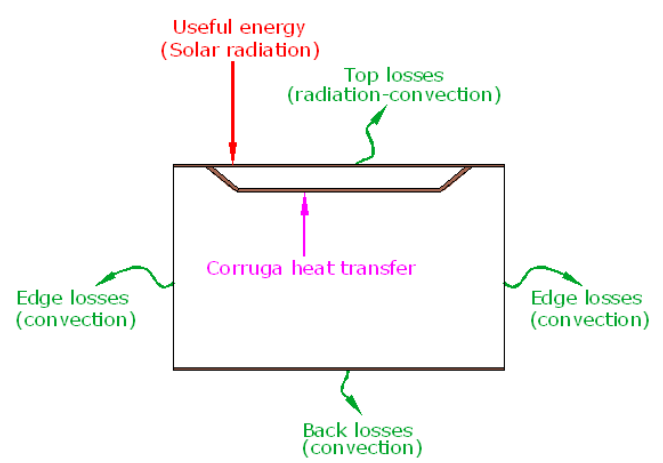

Fig. 1. Sketch of energy losses in the collector.

The stationary heat equation [1] is then numerically solved together with boundary conditions accounting for the energy losses through the surrounding area. On the 
plate, the absorbed solar irradiance is taken into account together with the heat losses through radiation and convection [see 3].

On the duct boundary, a convective boundary condition is considered using the mean fluid temperature which is computed solving the one-dimensional convective heat equation in the fluid with the useful heat transferred from the duct to the fluid as a source.

This model was implemented and solved by a finite element method in Comsol Multiphysics [2]. For stationary conditions, Table I shows the data for the numerical simulation and Table II the results for the main thermal parameters that characterize the behaviour of the collector. Figure 2 shows how temperature is distributed along the cross-section and, in Figure 3, the computed collector efficiency line is presented.

Table I. - Data for the numerical simulations

\begin{tabular}{|l|c|}
\hline$(\tau \alpha)$ & 0.87, single glass \\
\hline Collector tilt angle & $0^{\circ}$ \\
\hline Ambient temperature & $20^{\circ} \mathrm{C}$ \\
\hline Fluid temperature & $20^{\circ} \mathrm{C}$ \\
\hline Flow rate & $0.01 \mathrm{Kg} / \mathrm{s}$ \\
\hline Irradiance & $1000 \mathrm{~W} / \mathrm{m}^{2}$ \\
\hline
\end{tabular}

Table I. - Results of the 2-D simulations

\begin{tabular}{|l|c|}
\hline Efficiency & $84.5 \%$ \\
\hline Slope & -3.021 \\
\hline Maximum surface temperature & $31.7^{\circ} \mathrm{C}$ \\
\hline Fluid temperature rise & $18.7^{\circ} \mathrm{C}$ \\
\hline Overall heat loss coefficient & $3.1 \mathrm{~W} / \mathrm{m}^{2} \mathrm{~K}$ \\
\hline Collector heat removal factor & 0.96 \\
\hline
\end{tabular}

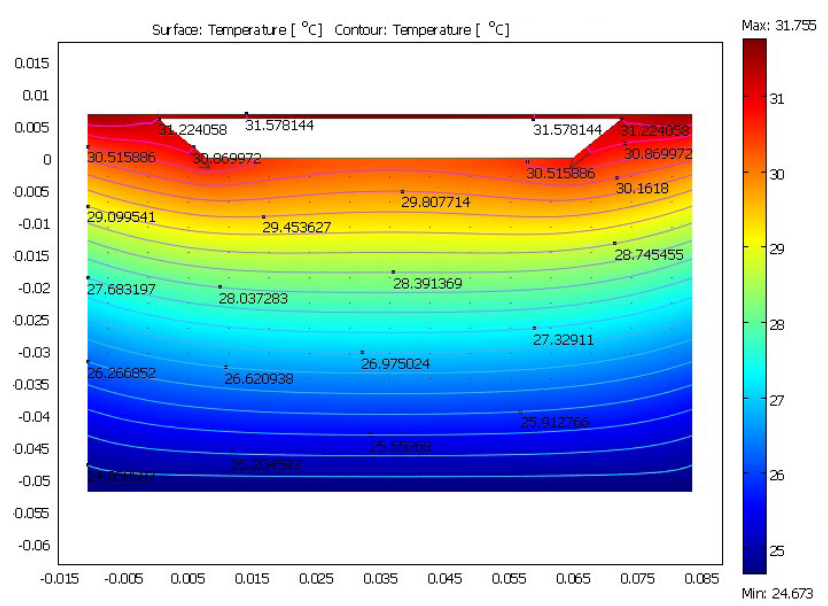

Fig. 2. Temperature distribution for the stationary thermal problem.

This methodology was extended to the transient case coupling:

- The two-dimensional transient equation in the collector cross-section.

- The one-dimensional convective heat equation modelling the temperature in the fluid.
- The differential equation governing the temperature rise on a unstratified tank.

Moreover, for the transient model, the irradiance (Fig. 3) and ambient temperature (Fig. 4) throughout one day are considered. The volume of the unstratified tank is $0.3 \mathrm{~m}^{3}$.

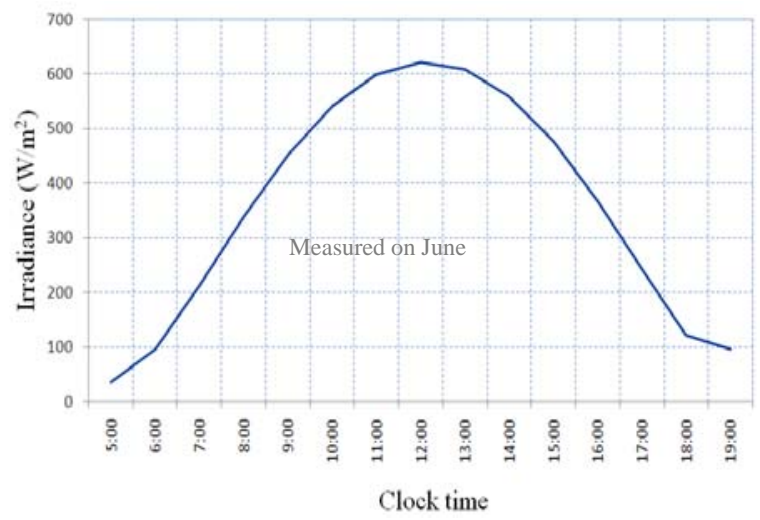

Fig. 3. Daily irradiance.

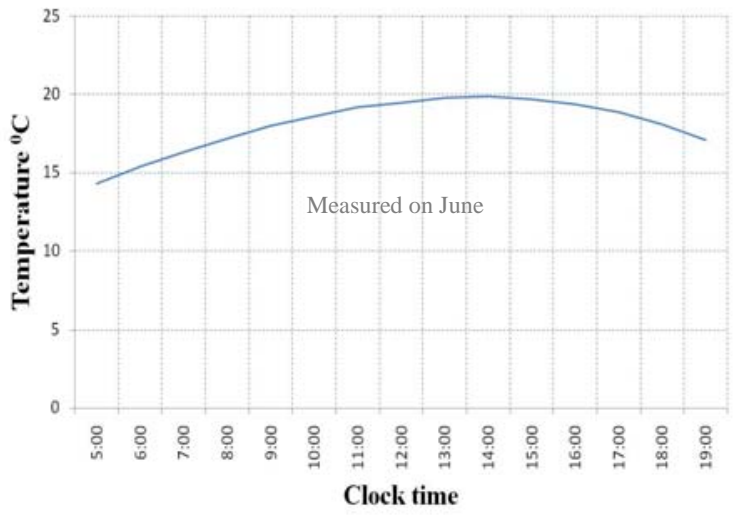

Fig. 4. Average daytime temperature.

With this transient analysis, one can observe the thermal behaviour of the collector at any given moment during the day, for instance, at midday, as shown in Figure 5.

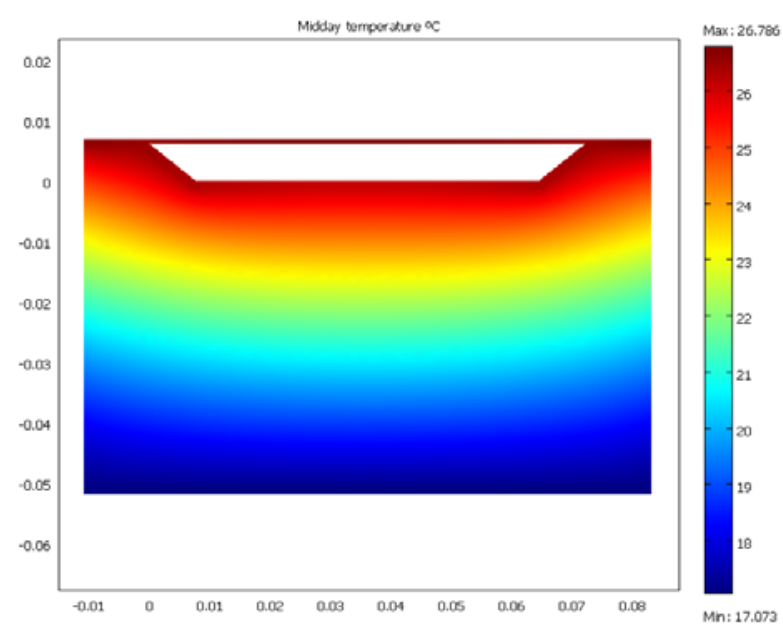

Fig. 5. Collector temperature at midday.

It is also possible to represent the useful energy transferred to the fluid during the simulation time (Fig. 6 ); the mean temperatures of the plate, fluid and tank 
(Fig. 7); and the instantaneous efficiency of the collector (Fig. 8).

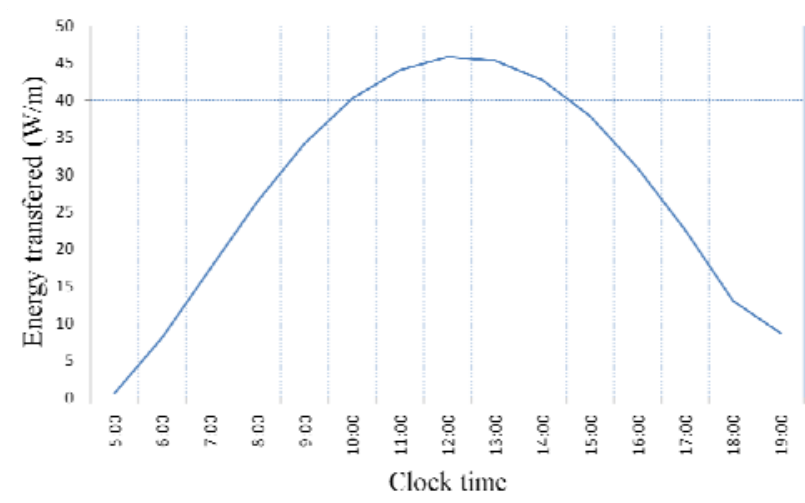

Fig. 6. Energy transferred to fluid.

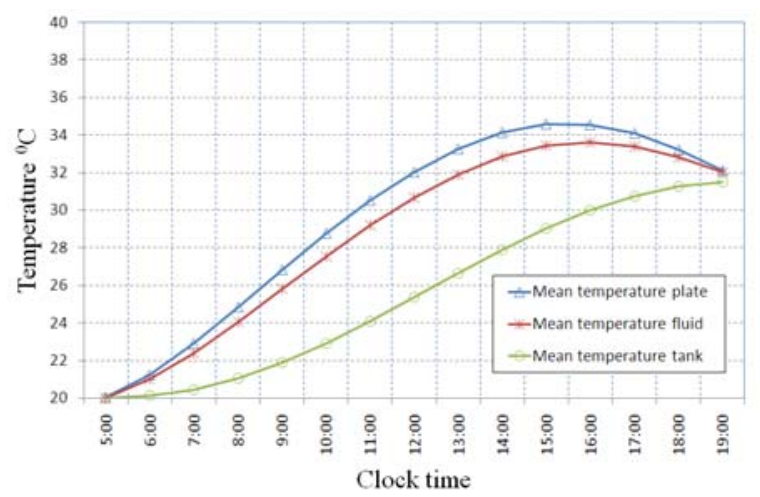

Fig.7. Mean temperatures of plate, fluid and tank.

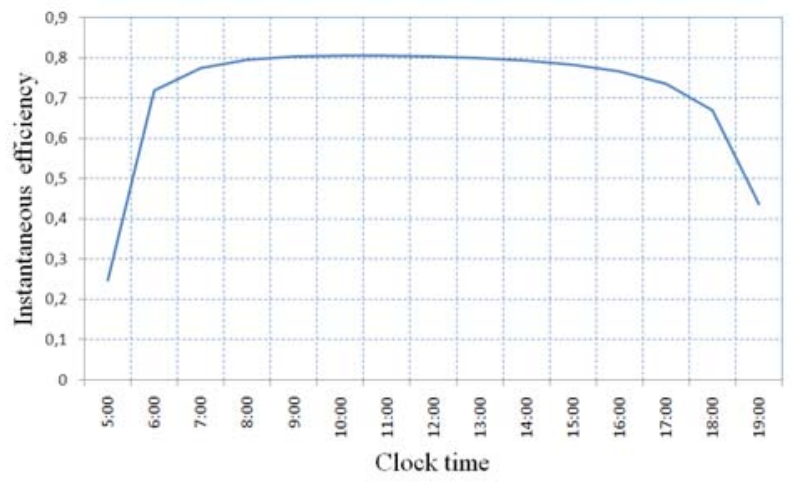

Fig. 8. Instantaneous efficiency of the collector.

\section{3D-dimensional hydrodynamic thermal simulations}

The computational domain is now the region occupied by the first three paths of the serpentine, as the mesh of the computational domain shows in Figure 9. The velocity of the fluid is governed by incompressible Navier-Stokes equations. The zero velocity on the lateral walls is considered and the inlet velocity is known.

Once the fluid velocity is computed, the stationary convective heat equation is numerically solved. The boundary conditions are analogous to the ones considered in the previous two-dimensional analysis.

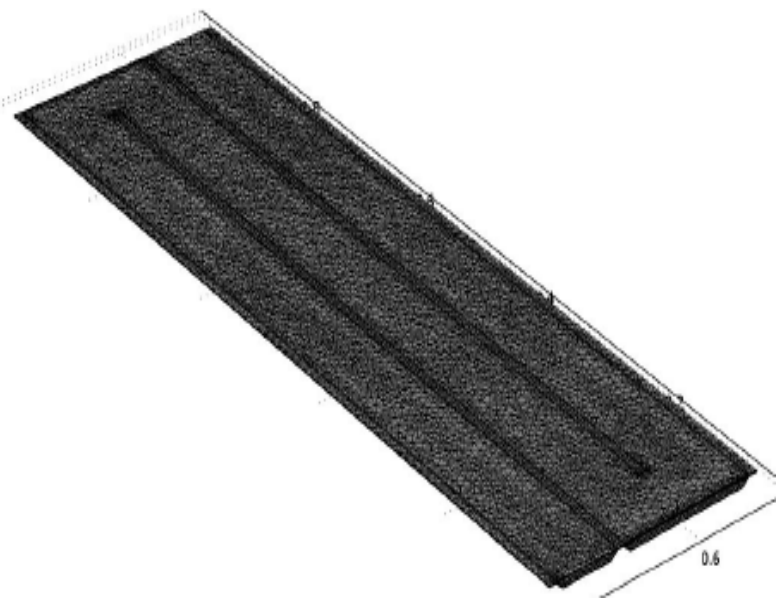

Fig.9 Mesh of 3-D computational domain.

In the next figures some results of the 3D computational model are shown. Figure 10 present the distribution of temperature and velocity field in the fluid along the path of serpentine under consideration.

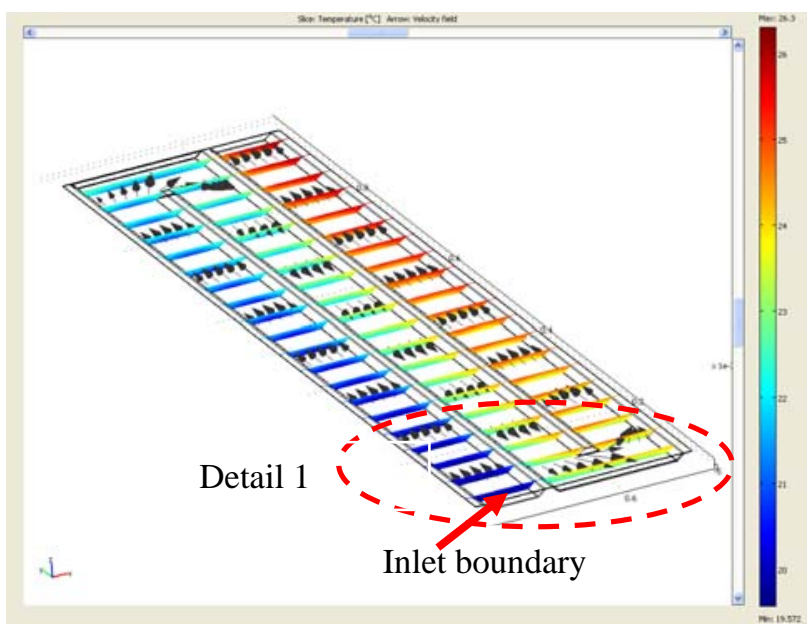

Fig.10 Temperature and velocity filed in the fluid channel.

Also the figure 11 shows with more detail the temperature and velocity filed at the turn of the serpentine.

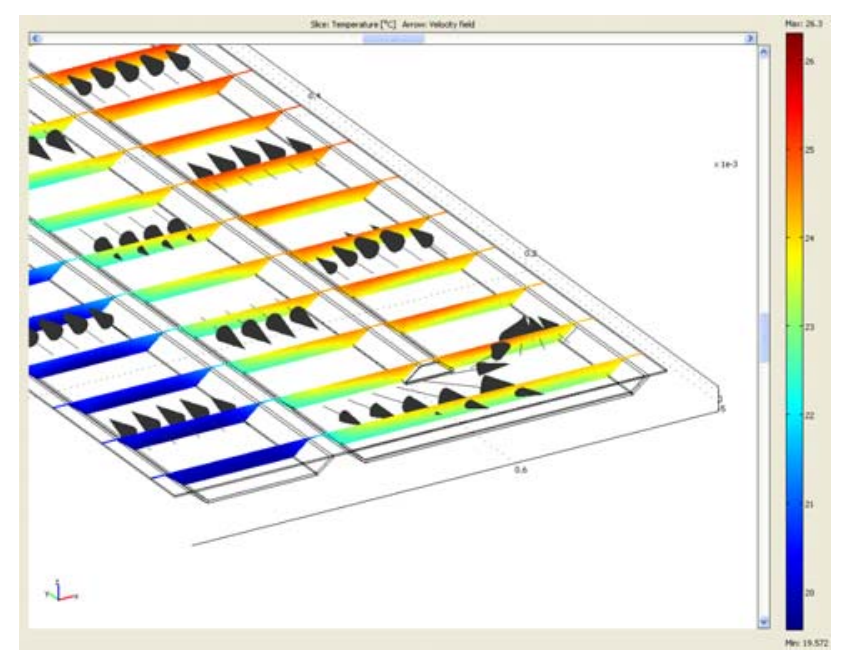

Fig.11 Detail 1 of figure 10. 
The following figures 12 and 13 display the temperature distribution in the fluid and in the absorber plate, respectively.

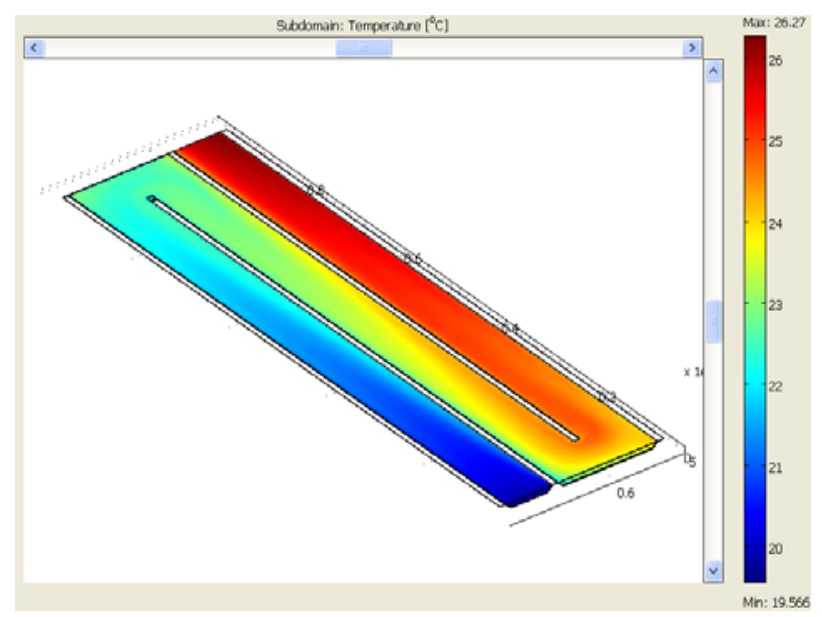

Fig.12 Fluid temperature.

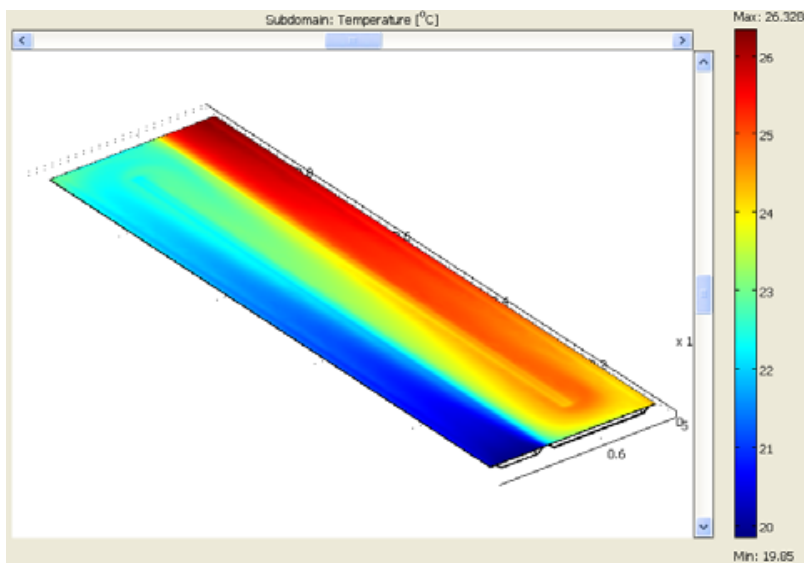

Fig.13 Top-plate temperature.

\section{Conclusion}

A new topology of solar collector is presented in this paper. It makes it possible for the fluid to have greater contact surface with the absorber plate and leads to an increase in collector efficiency. Moreover, as the solar collector is made in aluminium, it is cheaper and more competitive in the market.

To obtain the characteristic thermal parameters for the collector, a numerical simulation was carried out using a finite element method. For the stationary analysis, an efficiency of $84.5 \%$ is obtained, with a maximum plate temperature of $31.7^{\circ} \mathrm{C}$. Another factor to consider is that the fluid temperature rises by $18.7{ }^{\circ} \mathrm{C}$, the overall loss coefficient is $3.1 \mathrm{~W} / \mathrm{m}^{2} \mathrm{~K}$ and the heat removal factor equals 0.96. Similar values were found for the transient analysis during one-day simulation.

Finally, the 3D thermal and hydrodynamic behaviour for one part of the serpentine was numerically simulated.

\section{References}

[1] Chapman, A. J., Fundamentals of Heat Transfer, Macmillan Publishing Company, New York (1987)

[2] COMSOL, www.comsol.com (2009)

[3] Duffie, J. A., Beckman, W.A., Solar Engineering of Thermal Processes, third ed. Wiley Interscience, New Jersey (2006).

[4] Eisenmann, W., Vajen, K., Ackermann H., "On the correlations between collector effciency factor and material content of parallel fow fat-plate solar collectors". Solar Energy 76, pp. 381-387 (2004).

[5] Hassan, M.M., Beliveau, Y., "Modelling of an integrated solar system". Building and Environment 43, pp. 804-810 (2008).

[6] Oliva, A.,Costa M., Segarra, C.D., "Numerical simulation of solar collectors: the effect of nonuniform and nonsteady state or the boundary conditions ". Solar Energy 5, pp. 359-373. (1991).

[7] Molero, N., Cejudo J.M., Domínguez F., "Numerical 3-D heat flux simulations on flat plate solar collectors". Solar Energy 83, pp. 1086-1092. (2009). 